\title{
Э.М. Думнова
}

\section{ПРОБЛЕМА ФОРМИРОВАНИЯ ИДЕНТИЧНОСТИ СКВОЗЬ ПРИЗМУ ПОСТМОДЕРНИСТСКОЙ ПАРАДИГМЫ}

\begin{abstract}
Рассматривается проблема формирования начиональной идентичности и ее альтернатив в обществе постмодерна. Обозначены конщептуальные основания исследования процесса идентификаџии с позииий постмодернистской парадигмы. На материалах сочиологического исследования, проведенного автором посредством метода интервьюирования, раскрывается спечифика формирования трансидентичности эмигрантов и трансэмигрантов, выявляются основные тенденции и закономерности данного процесса в глобализированном мире.

Ключевые слова: транснациональная идентичность, национальная идентичность, общество постмодерна, сингулярность, делокализация идентичности.
\end{abstract}

\section{Парадигмальный статус проблемы}

Поворот к постмодерну обозначил новое пространство исследования и пересмотр результатов изучения ряда социально-философских проблем, в число которых входит и проблема формирования идентичности.

Исследование идентичности модерна способствовало выявлению тех закономерностей и механизмов ее формирования, которые впоследствии подверглись трансформации. Объективная актуализация постмодернистской парадигмы в изучении данной проблемы объясняется переходом к качественно новой современности. Расширение жизненного пространства и его реструктуризация детерминировали возникновение новых идентификационных практик. В обществе постмодерна формирование идентичности становится весьма вариативным. Данный процесс реализуется в формате различных идентификационных моделей. Это стало возможным по причине утраты структурой центра, именно децентрация общества задает новые потенции и тенденции идентификации социального субъекта. На смену структурированности социальной системы приходит аструктурность, лежащая в основе новых принципов развития. В этой связи в рамках современного социальнофилософского дискурса идентичность рассматривается согласно принципам сингулярности.

Понятие «сингулярность» (от лат. «singulus» - «одиночный, единичный») в философии обозначает единичность, неповторимость чего-либо - существа, события, явления. Данное понятие широко используется в работах современные французских философов-постмодернистов, в частности Жилем Делезом. В работе «Логика смысла» Ж. Делез трактовал сингулярность как событие, порождающее смысл и носящее точечный характер. «Это поворотные пункты и точки сгибов; узкие места, узлы, преддверия и центры; точки плавления, конденсации и кипения; точки слез и смеха, болезни и здоровья, надежды и уныния, точки чувствительности». Ж. Делез, выделяя свойства сингулярности, отмечает следующее: «Она совершенно безразлична к индивидуальному 
и коллективному, личному и безличному, частному и общему и к их противоположностям. Сингулярность нейтральна» [1. С. 78-80]. Например, сингулярностью может характеризоваться идентификация как группового, так и индивидуального субъекта.

Но при этом, «оставаясь конкретной точкой, событие неизбежно связано с другими событиями. Поэтому точка одновременно является и линией, выражающей все варианты модификации этой точки и ее взаимосвязей со всем миром [2].

Представляется целесообразным рассмотреть развитие структуры согласно принципам сингулярности в рамках синергетического подхода. Сингулярности проявляют себя в условиях нелинейного развития системы. Диссипативная структура возникает в результате открытости системы и предполагает взаимообмен энергией с окружающей средой. Так, система (социальный субъект) оказывается подверженной разного рода внешним воздействиям, что в итоге исключает ее дальнейшее функционирование по принципам каузальности и приводит ее к нелинейному варианту развития.

В контексте данной статьи в качестве диссипативной системы и объекта исследования выступает социальный субъект (индивидуальный или групповой). Поскольку он функционирует и идентифицируется в условиях социума, мы будем рассматривать социальный субъект относительно общества как подсистему и систему. Итак, социальный субъект попадает в условия децентрированной социальной системы, оказывающей на него непосредственное разностороннее воздействие, что приводит его в состояние флуктуаций и вхождению в зону бифуркации. Там и возникает ситуация выбора возможного варианта дальнейшей траектории его развития, т.е. объективация конструктивности хаоса. Малейшее воздействие на подсистему в таком состоянии может привести к ее непредсказуемой реакции в виде выбора одного из возможных сценариев развития, что выступает проявлением сингулярности.

Общество постмодерна, в рамках которого реализуются различные идентификационные практики, характеризуется расширением пространства повседневности индивида, которому также присущи утрата единого центра и, как следствие, диффузность и делокализованность. Данные характеристики жизненного пространства современного человека становятся особенно рельефными в условиях миграции. Переезд в другую страну на длительное время или на постоянное место жительства предполагает именно расширение жизненного пространства, а не только наполнение его новым содержанием или перекраиванием, поскольку связь с родиной так или иначе продолжает существовать в определенном формате. Аналогично миграционным процессам, детерминирующим феномен трансэмигрантов, эмиграция является отправной точкой формирования трансэмигрантов и, соответственно, трансидентичности. Как отмечают западные исследователи проблемы миграции, использование термина «трансмигранты» обусловлено тем, что мигранты «развивают и поддерживают множественные семейные, экономические, социальные, организационные и политические отношения, пересекающие границы» $[3,4]$.

Индивид и сообщества являются сингулярными, поскольку способны к дискурсу. При расширении пространства повседневности индивида складываются новые условия дискурса. В обществе постмодерна происходит непрерывная коммуникация - полилог между сингулярностями, в результате чего 
рождаются новые непредсказуемые смыслы и значения [5. С. 91-100]. Как отмечает современный российский исследователь Е.В. Пилюгина, «сингулярности предстают как события, источники и результаты событий. <..> Сингулярности никогда не являются конечным элементом, включая и включаясь в другие сингулярности, составляя конфронтации, или, напротив, синергию с другими сингулярностями» [6. С. 6]. Сингулярный мир Ж. Бодрияр характеризует как «порядок внутри беспорядка» [7. С. 30]. Имплозия (внутренний взрыв) как способ существования значений сингулярностей предполагает деконструкцию прежних значений и конструкцию новых.

В итоге существования индивида в условиях сингулярного мира формируется транспарентное сознание («обнуленное»), готовое для заполнения новыми смыслами и значениями. В связи с этим процесс идентификации в обществе постмодерна утрачивает свои прежние закономерности. Индивид не имеет точки опоры, которая стала бы отправной точкой идентификации, поскольку общество постмодерна характеризуется постоянным распадом, деконструкцией (Ж. Деррида) с последующей конструкцией и реконструкцией смыслов, идей, морали и ценностей в целом [8]. Новые социальные практики как элементы социальных процессов эпохи постмодерна, в числе которых глобализация, миграция, детерминировали соответствующие ей виды идентичности: транснациональную, бинациональную. Это явилось следствием трансформации традиционной национальной идентичности.

\section{Формирование идентичности в условиях постмодерна}

Для общества посмодерна характерно крисизное мироощущение в силу его нестабильности, «пластичности», многозначности происходящих событий и социальных процессов, что в совокупности представляет основу его перманентного распада, который в рамках постмодернистской парадигмы рассматривается как условие жизнеспособности и, в частности, рождения новых идентичностей [9]. Фрагментаризация идентичностей, их контекстуальность детерминируют объективную необходимость использования новой методологии для их научной разработки. Мы разделяем точку зрения современных петербуржских исследователей О. Бредниковой и О. Ткач о «смене парадигмы идентификации с местом и увеличении разнообразия парадигм идентификации» [10. С. 76]. Представляется необходимым в контексте комплексной парадигмы выделить дополнительные маркеры идентичности, что позволит воссоздать (конструировать) относительно целостную картину идентификации и ее результатов применительно к сообществу эмигрантов. Исходя из исследования национальной, а также транснациональной и бинациональной идентичностей как ее альтернатив, мы выделяем следующие маркеры идентичности: язык, религию, обычаи и традиции, политическую активность, концепцию родины.

Изучение вопроса сохранения национальной идентичности и формирования трансидентичностей в условиях трансмиграции предполагает использование данных социологического исследования, проведенного автором в апреле - мае 2017 г. Данное исследование проводилось в рамках качественного подхода с применением методов глубинного интервью и серии формализованных интервью. Основными информантами / исследовательскими кей- 
сами стали восемь эмигрантов, переехавших в постсоветский период из России в США, страны Западной Европы, Израиль, Канаду, Австралию.

В соответствии с заявленными критериями выборки все информанты получили высшее образование в России, принадлежат к прослойке интеллигенции, уехали в другую страну в зрелом возрасте и проживают там не менее трех лет и заняты интеллектуальным трудом. Материалы проведенных интервью позволяют проследить некоторые тенденции относительно изменения жизненного пространства информантов как базового условия трансформации механизмов идентификации и получения соответствующих результатов данного процесса.

Трансидентичность можно определить некоторой размытостью, не свойственной, например, национальной идентичности, что выражается в ее диффузности и делокализованности. Эти качества новой идентичности сформировались в результате проекции на нее свойств пространства повседневности, являющегося средой ее формирования. Пластичность и децентрация транснациональной идентичности, прежде всего, обусловлены наличием и поддержанием родственных, дружеских и прочих социальных связей трансмигрантов с людьми, оставшимися на их родине. Большинство опрошенных сказали, что на родине остались их родители и они видятся с ними 1-2 раза в год, приезжая на 1-2 недели. При этом следует отметить что отношения поддерживаются в виртуальном формате. Так, одна из информанток, отвечая на вопрос о том, как часто она видится с родителями и другими родственниками, говорит: Виртуально - каждую неделю. Физически в среднем раз в год (Юлия, 25 лет, Дания).

Языковой фактор играет значительную роль в формировании трансидентичности. Так, в ходе наших бесед выяснилось, что многие информанты состоят в браке с представителем другой национальности и при этом проживают в стране, не являющейся родной ни одному из супругов. Вследствие этих обстоятельств в их лингвистическом арсенале целых три разговорных языка, а у некоторых информантов даже больше, что связано с их этнической принадлежностью. Например, уроженка Казахстана, получившая образование на родине и в США, на вопрос: На каком языке вы чаще общаетесь? - ответила: На английском и русском языках. Реже на венгерском и казахском языках. На английском - с супругом и друзьями, на русском - с русскоязычными родственниками, знакомыми и друзьями. На венгерском - со свекром и свекровью, с соседями и в общественных местах. На казахском реже всего - с казахскоязычныли родственниками (Корлан, 32 года, Венгрия).

Другая информантка, получившая образование в России и Германии, ответила следующее: Английский - 90\% времени - с коллегами и мужем. Русский 5\% времени, с русскими друзьями в Европе или в письменных коммуникациях и с родителями. Датский - 5\% времени - бытовые коммуникации в публичных местах города, магазинах, кафе (Юлия, 25 лет, Дания).

Еще одним фактором формирования трансидентичности является сохранение потребности в общении на родном языке с представителями своего народа, о чем заявили в интервью более половины информантов. При этом данная потребность никак не связана с их отношением к родной стране и, соответственно, не является маркером национальной идентичности, а скорее подчеркивает фрагментаризацию идентичности и усиление значимости этни- 
ческой идентичности, носящую изначально делокализованный характер, что обеспечивает более высокий уровень ее стабильности и устойчивости. Некоторые информанты отметили по этому поводу следующее:

- В месте, где мы живем, у меня есть и русскоговорящче друзья (Фируза, 26 лет, Шотландия).

- ...я достаточно общаюсь с представителями своего народа. Потребность возникает из-за общих культурных иенностей и сложившегося поведения. С людьми из стран СНГ намного проще общаться, они быстрее идут на контакт, гостеприимнее, открытее, чем местный народ (Корлан, 32 года, Венгрия).

- Иногда у меня есть острая потребность послушать русскую речь, я обычно это восполняю просмотром русскоязычных фильмов. Быстрое освоение русского языка моим мужем тоже значительно восполняет мои потребности пошутить и поболтать на русском. Я бы не сказала, что у меня когда либо были сложности самовыражения на иностранном языке, но иногда я скучаю по живым русским фразам и собственно изобретенным выражениям, которые могут быть понятны только носителям русского языка (Юлия, 25 лет, Дания).

Полученные ответы демонстрируют устойчивость ментальной матрицы русских эмигрантов, что выражается в сохранении социокультурных установок, поведенческих стереотипов и стремлении к их воспроизводству. Поддержание сформированной ментальности происходит посредством сохранения и использования родного языка как инструмента реализации ментальных особенностей. Данные обстоятельства являются основой сохранения этнической идентичности, которая органично вписывается в процесс формирования трансидентичности эмигрантов. Исследование показало, что устойчивость этнической идентичности в большей степени свойственна представителям малых этносов, в составе нашей выборки это выходцы из бывших союзных республик: Корлан (Казахстан), Фируза (Таджикистан), Евгений (Узбекистан).

Сохранение этнической идентичности не противоречит делокализации идентичности и ослаблению идеологии «объединяющих мест». Зависимость от места утрачивается на фоне глобализационных процессов и увеличения свободы индивида в широком смысле, в том числе свободы перемещения, выбора места жительства. Многие информанты, покинув родину, сменили несколько стран проживания. Причины этого лежат в сфере как профессиональных, так и семейных отношений. При этом ни один из опрошенных не выразил желания вернуться на родину, во многом это связано с причинами отъезда. Хотя они не были описаны ими в алармистских категориях, в целом все же носят негативный оттенок, что связано, в частности, с ухудшением их социального самочувствия на родине вследствие развала СССР, отсутствием достойно оплачиваемой работы и сложностями трудоустройства в соответствии со специальностью. Поскольку все информанты реализовали себя в профессиональной сфере на текущее время, перемещение многих в европейском пространстве, а также переезд из США в Европу были связаны именно с поиском профессиональных возможностей и перспектив карьерного роста. Кроме того, часть из них создали семью, уже покинув родину, и определенным образом их переезды зависели от обстоятельств, в которых оказался супруг. 
Анализ интервью показывает, что жизненные сценарии трансмигрантов отличаются плюральностью, т.е. они могут развиваться по разным траекториям, выбор которых носит случайный (сингулярный) характер. Результатом этого является приобретение колоссального жизненного опыта, лежащего в основе трансформации их концепции родины. Традиционно родина - это прежде всего пространственные репрезентации. Архетип родины объективируется в социопространственной идентификации, где имеют значение как топос, так и культура, особенности социальных интеракций. Расширение миграций и других видов пространственной мобильности приводит к возникновению плюральности концепций родины, что обусловлено социальным конструированием действительности в разрезе постмодернистских социальных практик индивидов.

Наше исследование позволило выявить сложность определения эмигрантами родины в условиях поделенной (фрагментарной) идентичности. При этом стали очевидными следующие тенденции в понимании родины информантами, выделенные на основе полученных типических групп ответов:

1. Делокализованность родины как результат фрагментаризации идентичности. Пространственный критерий идентификации и, как следствие, определения родины уступает позиции социальному, мировоззренческому и идеологическому. В основе определения родины в этом случае лежит императив социальной идентичности. Информанты отмечают, что родина для них это ...там где комфортно и хочется продолжать жить; ...mам, где я и мое сознание. Во многом такая позиция связана с причинами переезда и возрастом, ее в основном разделяют эмигранты, которые оказались за границей в связи с получением образования и социальный рост и личностное становление которых происходили именно там.

2. Локализация родины и сохранение символической ценности ряда ее материальных и духовных составляющих, например город, природа, еда, язык. Данная типическая группа ответов представлена мнениями старшей возрастной категории информантов (40-50 лет), чье детство и юность прошли в СССР. Несмотря на то, что они эмигрировали более десяти лет назад, в их ответах прослеживается четкая пространственная идентификация родины. Определяющим критерием родины у многих из них являются ассоциации с детством и территорией, где оно проведено.

3. Утрата смысла понятия родины.

Представляется важным, что формирование понимания родины когерентно трансформации национальной идентичности. Так, информанты, чьи ответы вошли в первую типическую группу, отметили, что стали осознавать себя частью русского народа, только когда переехали из России.

Вторая группа информантов однозначно идентифицирует себя с русским народом, поддерживая традиционную концепцию родины и сохраняя национальную идентичность. Третья группа - это представители новой тенденции формирования трансидентичности. Они отметили, что не ощущают себя частью своего родного народа.

Проведенное исследование позволило прийти к следующим выводам.

Во-первых, децентрация социальной системы привела к возникновению нового пространства повседневности с характерными для него механизмами и результатами идентификации, когерентными обществу постмо- 
дерна, что объективировалось в социальных практиках эмигрантов и трансэмигрантов.

Во-вторых, конструктивный хаос и плюральность системы детерминировали альтернативные национальной виды идентичности, что привело к размытости смысла понятия родины и формированию новых концепций родины.

В-третьих, ослабление национальной идентичности, ее делокализованность, подкрепленная нежеланием абсолютного большинства информантов возвращаться в родную страну, происходит параллельно с возрастанием для них значимости этнической идентичности.

В-четвертых, общество постмодерна детерминировало нелинейность и плюральность жизненных сценариев, в основе реализации которых лежат принципы сингулярности, что объективируется в биографических сценариях трансэмигрантов и формировании новой ментальности как основы социопространственной идентичности.

\section{Литература}

1. Делез Ж. Логика смысла: пер. с фр. Фуко М. Theatrum philosophicum: пер. с фр. Москва: Раритет; Екатеринбург: Деловая книга, 1998. 480 с.

2. Что такое сингулярность, или Почему история человечества однажды станет непредсказуемой. URL: https://theoryandpractice.ru/posts/6981-chto-takoe-singulyarnost-ili-pochemuistoriya-chelovechestva-odnazhdy-stanet nepredskazuemoy/ (дата обращения: 29.04.2017).

3. Glick Schiller N., Basch L., Szanton Blanc C. Transnationalism: A new analytical framework for understanding migration // Glick Schiller N., Basch L., Szanton Blanc C. (eds). Towards a Transnational Perspective on Migration: Race, class, ethnicity and nationalism reconsidered. New York: New York Academy of Science, 1992. P. 1-24.

4. Glick-Schiller N., Basch L., Szanton Blanc C. From Immigrant to Transmigrant: Theorizing Transnational migration: Migration and Transnational Social Spaces. Aldershot: Ashgate, 1999. P. 73-105.

5. Нанси Ж.Л. О событии // Философия Мартина Хайдеггера и современность. М.: Наука, 1991. C. $91-100$.

6. Пилюгина Е.В. Состояние постмодерна: сингулярность бытия, транспорентность сознания и вирусы тоталитарных идей // Studia Humanitatis. 2014. № 1-2. URL: www.st-hum.ru (дата обращения: 30.10.2017).

7. Бодрияр Ж. Прозрачность зла. М.: Добросвет, 2000. 258 с.

8. Деррида Ж. Письмо и различие / пер. с фр.; под ред. В. Лапицкого. СПб.: Академический проект, 2000. $432 \mathrm{c.}$

9. Судас Л.Г. Постмодернизм. URL: http://www.chem.msu.su:8081/ (дата обращения: 25.04.2017).

10. Бредникова О., Ткач О. Дом для номады // LABORATORIUM. Журнал социальных исследований. 2010. № 3. С. 72-95.

Dumnova Elnara M. Novosibirsk State University of Economics and Management, Novosibirsk military Institute of national guard troops (Novosibirsk, Russian Federation)

E-mail: dumnova79@yandex.ru

DOI: $10.17223 / 1998863 \mathrm{X} / 41 / 5$

THE PROBLEM OF IDENTITY FORMATION THROUGH THE PRISM OF POSTMODERN PARADIGM

Key words: transnational identity, national identity, postmodern society, singularity, delocalization of identity.

The article discusses the problem of national identity formation and its alternatives in modern society. The actualization of postmodern paradigm in studying the problems of identity is justified and theoretical and methodological foundations of investigating identification and its outcomes in postmodern society in the context of non-linear development are revealed. Identity formation in postmodern society becomes very changeable, this process is implemented in various identity patterns. Post- 
modernity is characterized by lack of structural properties, decentration and plurality; identity is thus viewed within the framework of the contemporary socio-philosophical discourse in the light of singularity principles. Singularity, as viewed by J. Deleuze, is a dot meaning-producing event. The individual everyday life space is expanded, a single center of this space is lost, causing diffuseness and delocalization. These characteristics of contemporary man life space become particularly prominent in the circumstances of migration, which is becoming global and determining formation of transidentities. The process of identification in postmodern society is losing its former regularities. The birth of new identities is undergoing in the circumstances of constructive chaos and is characterized by fragmentation and contextuality. The problem of preserving national identity and forming transidentities in the conditions of transmigration is discussed by the author on the basis of materials of sociological survey, conducted by the author in April - May 2017, using qualitative approach and methods of deep interview, as well as a series of formalized interviews. Major informants were emigrants, which moved from Russia to the US, Western Europe, Israel, Canada and Australia in the post-Soviet period. The analysis of the data obtained made it possible to identify a number of tendencies, including weakening of national identity, its delocalization, the growth of importance of ethnic identity, the emergence of plurality of the concepts of Motherland, non-linear character and plurality of life scenarios. The implementation of these scenarios is based on singularity principles, objectified in biographical scenarios of transemigrants and the formation of new mentality.

\section{References}

1. Deleuze, J. (1998) Logika smysla [Theatrum philosophicum]. Translated from French by M. Foucault. Moscow: Raritet; Ekaterinburg: Delovaya kniga.

2. Onegina, E. (n.d.) Chto takoe singulyarnost' ili pochemu istoriya chelovechestva odnazhdy stanet nepredskazuemoy [What is the singularity or why the history of mankind will become unpredictable one day?] [Online] Available from: https://theoryandpractice.ru/posts/6981-chto-takoesingulyarnost-ili-pochemu-istoriya-chelovechestva-odnazhdy-stanet nepredskazuemoy/. (Accessed: 29th April 2017).

3. Glick Schiller, N., Basch, L. \& Szanton Blanc, C. (1992) Transnationalism: A new analytical framework for understanding migration. In: Glick Schiller, N., Basch, L., Szanton Blanc, C. (eds). Towards a Transnational Perspective on Migration: Race, class, ethnicity and nationalism reconsidered. New York: New York Academy of Science. pp. 1-24.

4. Glick-Schiller, N., Basch, L. \& Szanton Blanc, C. (1999) From Immigrant to Transmigrant: Theorising Transnational Migration. In: Priers, L. (ed.) Migration and Transnational Social Spaces. Aldershot: Ashgate. Pp. 73-105.

5. Nancy, J.-L. (1991) O sobytii [About the event]. In: Motroshilova, N.V. (ed.) Filosofiya Martina Khaydeggera i sovremennost' [Philosophy of Martin Heidegger and modernity]. Moscow: Nauka. pp. 91-100

6. Pilyugina, E.V. (2014) Sostoyanie postmoderna: singulyarnost' bytiya, transparentnost' soznaniya i virusy totalitarnykh idey [The state of postmodernity: singularity of being, transparency of consciousness and viruses of totalitarian ideas]. Studia Humanitatis. 1-2. [Online] Available from: www.st-hum.ru. (Accessed: 30th October 2017).

7. Baudrillard, J. (2000) Prozrachnost' zla [Transparency of Evil]. Translated from French by L. Lyubarskaya, E. Markovskaya. Moscow: Dobrosvet.

8. Derrida, J. (2000) Pis'mo i razlichie [Writing and Difference]. Translated from French by V. Lapitsky. St. Petersburg: Akademicheskiy proekt.

9. Sudas, L.G. (n.d.) Postmodernizm [Postmodernism]. [Online] Available from: http://www.chem.msu.su:8081/. (Accessed: 25th April 2017).

10. Brednikova, O. \& Tkach, O. (2010) Dom dlya nomady [House for the nomads]. LABORATORIUM. Zhurnal sotsial'nykh issledovaniy - Laboratorium. Social Research Journal. 3. pp. $72-95$. 